\title{
Series Voltage Sag Compensation Using Series Type SMES with Open-Circuit Protection
}

\author{
Sumate Naetiladdanon* Student Member \\ Toshifumi Ise* Member \\ Hideki Fujita** $^{* *} \quad$ Member
}

In this paper, the voltage sag compensation using series type SMES (Superconducting Magnetic Energy Storage) with open-circuit protection is proposed. The voltage sags and momentary interruptions during the fault occurred can be mitigated. For open-circuit protection, the faulted incoming line is disconnected and the new current path is made. The control scheme is proposed for voltage sag compensation and open-circuit protection. Simulations of voltage sag compensation and open-circuit protection demonstrated the validation of the proposed circuit and control sequence of switches.

Keywords: series voltage sag compensator, open-circuit fault protection

\section{Introduction}

Voltage sags are considered as the dominant and unavoidable disturbances affecting power quality concerning by both utilities and industrial consumers. The most effective way to mitigate for voltage sag is to apply voltage sag mitigation equipment at the customer site. Among the several novel voltage sag mitigation equipment, a power electronic converter-based series compensator is recognized to be the most effective equipment that can be used for voltage sag mitigation $^{(1)-(4)}$. The compensation is based on injecting backfilling voltage in series with the incoming supply network during the voltage sag event. Thereby, the voltage on the load side can be restored to the desired amplitude and waveform even when the source voltage is unbalanced or distorted. The series compensator can inject the missing voltage instantaneously and tightly regulate voltage at load terminal. The appropriate voltage injection algorithm can prevent the discontinuity of the load-side voltage from sudden phase angle shift and voltage magnitude dip of the source voltage. As the compensator has to supply active power as well as reactive power, some kind of energy storage such as a superconducting magnet is needed. The injected energy minimization algorithm for voltage sag compensation can be included in the control scheme as well ${ }^{(4)(5)}$. However, the series voltage sag compensator cannot compensate during the open-circuit condition, because it needs a closed path for the load current ${ }^{(6)}$.

For example, in the transmission and distribution system employing with a transfer switch, the power usually transfers to the load through the main feeder. When a fault occurs in the transmission line of the main feeder, the transfer switch will switch the main feeder to the sub feeder. That is, the interruption duration can be significantly reduced; although,

\footnotetext{
* Department of Electrical Engineering, Osaka University

2-1, Yamada-oka, Suita 565-0871

** Research and Development Division, CHUBU Electric Power Co., Inc.

20-1, Aza Kitasekiyama, Odaka-cho, Midori-ku, Nagoya 459-8522
}

the load has to suffer the momentary interruption due to the open circuit during this transfer interval. Conventional series voltage sag compensators cannot work under this condition.

The authors proposed the series voltage sag compensator with open-circuit protection. During the load transfer interval, the series voltage sag compensator with open-circuit protection will provide the continuous current path between the compensator and load and cut off the incoming line current path, then it can overcome the open-circuit condition. Operation of the system is demonstrated by simulation.

\section{Circuit Configuration}

2.1 Typical Series Voltage Sag Compensator The series voltage sag compensator consists of a voltage source converter (VSC) in series with the supply voltage, as shown in Fig. 1. The voltage at the load terminal equals the sum of supply voltage and the output voltage of the controller. A converter transformer is used to connect the output of the voltage-source converter to the system. A relatively small capacitor is present on dc side of the converter. The voltage over this capacitor is kept constant, by exchanging energy with the energy storage reservoir. This type of compensator

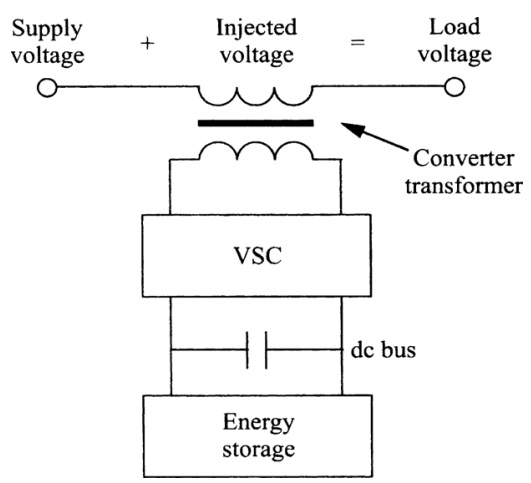

Fig. 1. Configuration of series voltage sag compensator 


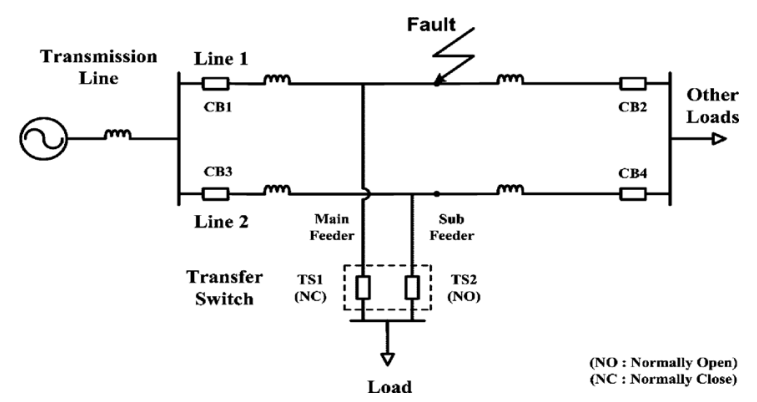

Fig. 2. Transmission system with a transfer switch

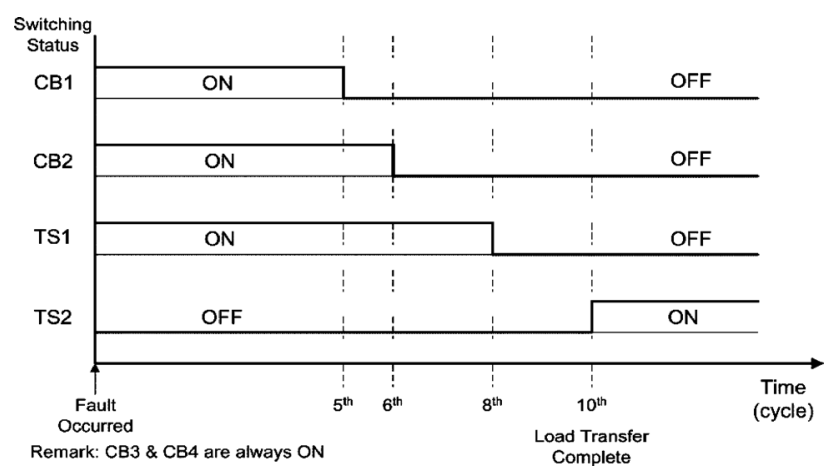

Fig. 3. Time chart of the switch operation

using a superconductor magnet as the energy storage device is called as a series type SMES (Superconducting Magnetic Energy Storage). The required output voltage is obtained by using a pulse-width-modulated switching pattern. The amount of energy storage depends on the power delivered by the converter and on the maximum duration of voltage sags. The compensator is typically designed for a certain maximum sag duration and a certain minimum sag voltage.

2.2 Transmission System with a Transfer Switch

The transmission system employing with a transfer switch connected to load is illustrated in Fig. 2. This is an example that a short interruption with open circuit could occur. Under the normal operation, the power transfers to the load from Line 1 through the main feeder. If the fault occurs in Line 1 , the circuit breaker will operate in order to clear the fault. As a result, the load will be transferred to Line 2 by using the transfer switch. It is assumed that the circuit breaker CB1 and CB2 will be opened after the fault detection, approximately in 5 and 6 cycles, respectively. Then, the transfer switch TS1 will be opened to cut off the main feeder at the $8^{\text {th }}$ cycle, and the transfer switch TS2 will be closed to connect Line 2 through the sub feeder at $10^{\text {th }}$ cycle, then the load transfer procedure is completed. Fig. 3 illustrates the time chart of the switch operation during the fault occurred in Line 1 . The open-circuit condition occurs from $6^{\text {th }}$ cycle to $10^{\text {th }}$ cycle.

\subsection{Proposed Circuit for Open Circuit Protection}

The requirements for the operation of compensator during the interruption are the continuous current path between the compensator and load and the cut-off current path back to the incoming line. The proposed schematic is shown in Fig. 4 and the proposed circuit of the series voltage sag compensator with open circuit protection is shown in Fig. 5.

For the fast response operation, the hybrid switch which comsists of a pair of anti-parallel thyristors and a high-speed

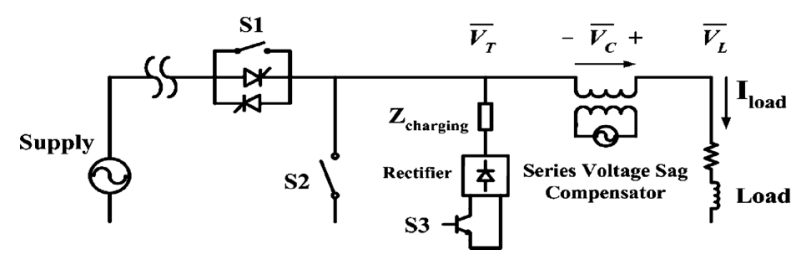

Fig. 4. Proposed schematic for open-circuit protection

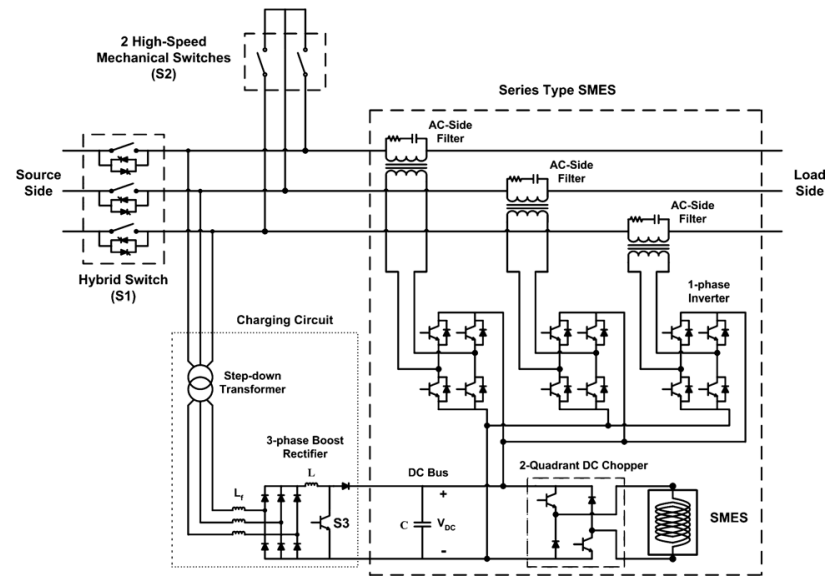

Fig. 5. Proposed circuit for open-circuit protection

mechanical parallel switch can be used as S1 to connect and disconnect the incoming line, because it can reduce the usual conduction losses and operate quickly. The opening operation is made within half cycle where the closing operation is almost instantaneous because of the use of anti-parallel thyristors. Two high-speed mechanical switches can be used as S2 for making the continuous current path with very low loss for 3-phase system. The mechanical switches for S2 and a part of S1 are assumed to be a high-speed mechanical switch whose opening time is less than $1 \mathrm{~ms}$ and closing time is less than $10 \mathrm{~ms}{ }^{(7)}$. The charging circuit is usually used for initial charging of the dc capacitor and the superconducting magnet, loss compensation of the circuit and compensation of lost energy during voltage sag compensation. The semiconductor switch at the 3-phase boost rectifier will be used as $\mathrm{S} 3$ for providing the continuous current path during the opening/closing transition of the switches $\mathrm{S} 1$ and $\mathrm{S} 2$. Because the ac voltage and current are rectified, the switch S3 can be used as a temporary return current path for the rectified dc current. The semiconductor switch S3 can be opened and closed almost instantaneously (less than $10 \mu \mathrm{s}$ ).

However, the use of charging circuit as a return-current path will cause power losses and voltage drop due to the impedance in the charging circuit (transformer leakage reactance $\left(\mathrm{L}_{\mathrm{Tr}}\right)$, winding resistance $\left(\mathrm{R}_{\mathrm{Tr}}\right)$, line inductor $\left(\mathrm{L}_{\mathrm{f}}\right)$, internal resisatance of diode rectifier $\left(\mathrm{R}_{\mathrm{D}}\right)$, dc inductor $(\mathrm{L})$ and internal resisatance of semiconductor switch $\mathrm{S} 3\left(\mathrm{R}_{\mathrm{sw}}\right)$ ).

During the occurrence of voltage sags, the load side voltage $\left(\bar{V}_{L}\right)$ is the sum of the supply side voltage $\left(\bar{V}_{T}\right)$ and the injected voltage $\left(\bar{V}_{C}\right)$, which can be expressed by

$$
\bar{V}_{L}=\bar{V}_{T}+\bar{V}_{C} \ldots
$$

During the incoming line disconnecting and connecting period, if switch $\mathrm{S}_{3}$ is closed and the charging circuit is used as the return path for load current, the supply side voltage $\left(\bar{V}_{T}\right)$ 
will become the voltage across the charging circuit and the injected voltage $\left(\bar{V}_{C}\right)$ will be the sum of the voltage across the charging circuit $\left(\bar{V}_{T}\right)$ and the load voltage $\left(\bar{V}_{L}\right)$, which can be expressed by

$$
\bar{V}_{C}=\bar{V}_{T}+\bar{V}_{L}
$$

The voltage across the charging circuit can be expressed by

$$
\begin{aligned}
\bar{V}_{T}= & {\left[\bar{I}_{C h}\left(R_{T r}+R_{D}\right)+\left(L_{T r} \frac{d \bar{I}_{C h}}{d t}+L f \frac{d \bar{I}_{C h}}{d t}\right)\right] } \\
& +\left[I_{D} R_{S W}+L \frac{d I_{D}}{d t}\right] \ldots \ldots \ldots \ldots \ldots \ldots
\end{aligned}
$$

where $\bar{I}_{C h}$ is the charging circuit current and $I_{D}$ is the dc side current. The first bracket term is referred to the ac side voltage and the second bracket term is referred to the dc side voltage that is equivalent to input voltage of diode rectifier. The load current $\left(\bar{I}_{\text {Load }}\right)$ is the sum of the charging circuit current and current flowing in switch $\mathrm{S} 1$ during disconnecting period, or current flowing in switch S2 during connecting period, and the charging circuit current is equal to load current when there is only the return-current path in the charging circuit. During these transitions, if the series compensator has the maximum injection voltage as the pre-sag load voltage (i.e. $100 \%$ injected voltage limit), the load voltage will experience a transient voltage sag from the voltage drop in the charging circuit. The illustration of voltages and currents behaviors for switching transition of S1, S2, S3 is shown in Fig. 6. After the fault occurs, the voltage sag at load is compensated as shown in Fig. 6(a). After the circuit breaker opens, the load will experience the interruption as shown in Fig. 6(b). The load voltage and current will decrease to zero if there is no return current path for load current where the power flow will reverse its direction if there is a return current path, such as at other loads. The interruption will be detected and switch S3 will be turned on as shown in Fig. 6(c). Then, the switch S1 will be turned off to disconnect the incoming line as shown in Fig. 6(d). The switch S2 will be turn on and switch S3 will be turned off as shown in Fig. 6(e) and 6(f), respectively.

The current rating on the ac side is the same as the load current multiplying with the transformer ratio (n) where the current rating on the dc side is the rectified load current multiplying with the transformer ratio (n). The impedance on the ac side of charging circuit should be small in order to reduce the voltage drop.

The minimum size of dc inductor for the continuousconduction mode of boost charging operation can be calulated by

$$
L_{\min }=\frac{V_{o}}{2 I_{o B, \max } * f_{s}} D(1-D)^{2}
$$

where $I_{O B, \max }$ is the maximum output current at the boundary of continuous-discontinuous conduction, $V_{o}$ is the output voltage of boost rectifier, $f_{s}$ is the switching frequency and $D$ is the duty ratio. The larger size of dc inductor may be used to ensure a continuous-conduction mode for the fast charging operation.

The dc side voltage during transitions is mostly affected by the voltage across dc inductor which can be expressed by

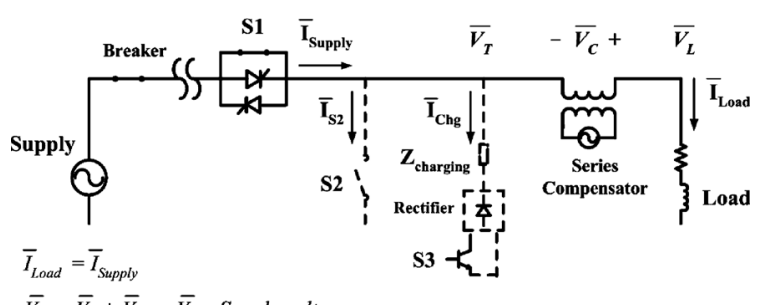

$\bar{V}_{L}=\bar{V}_{T}+\bar{V}_{C}, \bar{V}_{T}:$ Supply voltage

(a) During voltage sag (S1-ON, S2-OFF, S3-OFF)

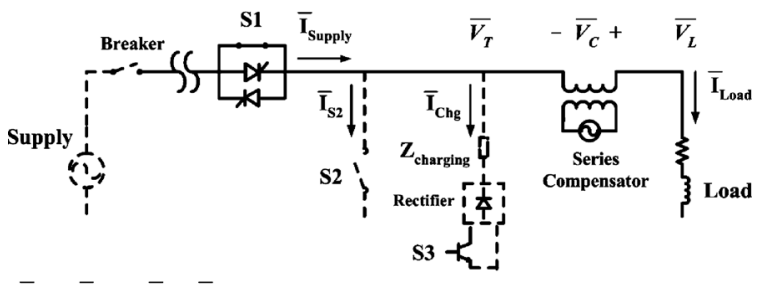

$\bar{I}_{\text {Load }}=\bar{I}_{\text {Supply }} \& \bar{V}_{L} \& \bar{V}_{T}$ (decreasing to zero) or Reverse Power Flow

(b) Interruption starts (S1-ON, S2-OFF, S3-OFF)

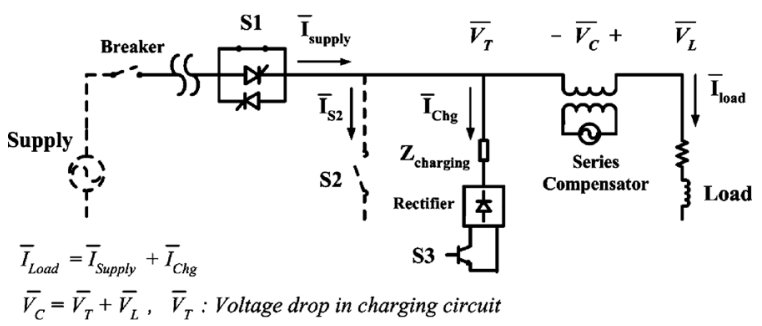

(c) After interruption is detected (S1-ON, S2-OFF, S3-ON)

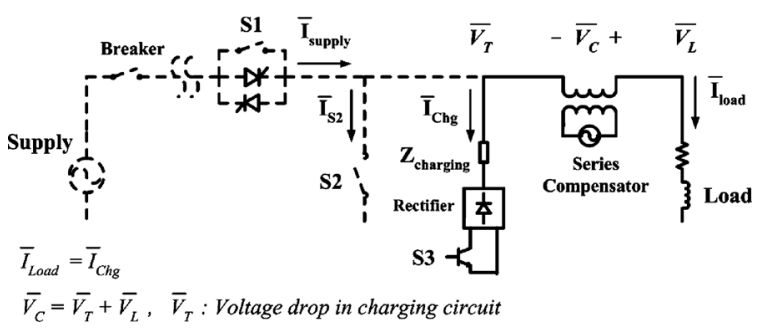

(d) During interruption (S1-OFF, S2-OFF, S3-ON)

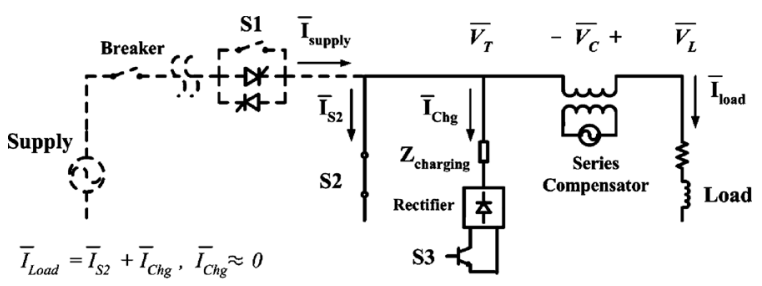

$\bar{V}_{C}=\bar{V}_{T}+\bar{V}_{L}, \quad \bar{V}_{T} \approx 0$

(e) During interruption (S1-OFF, S2-ON, S3-ON)

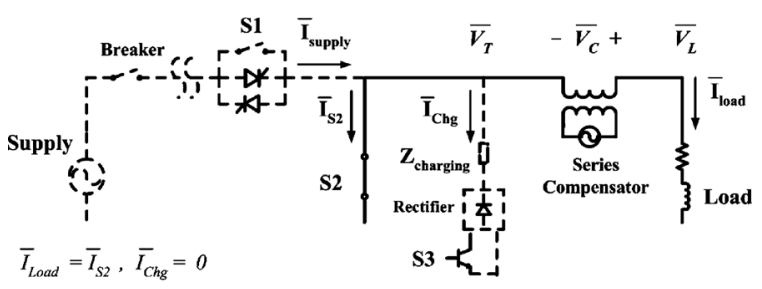

$\overline{V_{C}}=\overline{V_{L}}, \overline{V_{T}}=0$

(f) During interruption (S1-OFF, S2-ON, S3-OFF)

Fig. 6. Illustration of voltages and currents behaviors for switching transition of S1, S2, S3

$$
V_{L d c}=L \frac{d I_{D}}{d t}
$$

The size of dc inductor should not be too large in order to 
limit this transient voltage drop. The maximum size of $\mathrm{dc}$ inductor is can be calculated by

$$
L_{\max }=\frac{V_{L d c, \max }}{d I_{D} / d t} \approx \frac{V_{L d c, \text { max }}}{\omega * I_{\text {Load,rectified }} * n}
$$

where $V_{L d c \text {, max }}$ is the maximum allowable magnitude of the voltage drop across dc inductor and $\mathrm{dI}_{\mathrm{D}} / \mathrm{dt}$ is the rate-of-rise of dc side current.

\section{Detection and Control Scheme}

3.1 Operation Modes Fig. 7 illustrates the flowchart of control algorithm of the series voltage sag compensator with open-circuit protection. The two operation modes consist of the voltage sag compensation mode and the interruption compensation mode. After the fault occurred in the transmission system, the voltage sag at the load will be detected. The voltage sag compensation at load will be operated until the voltage recovery occurs then the compensator will enter the standby mode. If the circuit breaker opens in order to clear the fault, the interruption condition will be detected. The incoming line will be cut off and the new current path will be made. The compensator will supply $100 \%$ AC voltage to the load. After the voltage recovery, the current path during compensation will be cut off and the incoming line will be connected again, then the compensator will enter the stand-by mode.

\subsection{Detection Method of Voltage Sag and Interrup-}

tion The voltage sag and interruption detection method used is based on the rms of the error vector voltage, which is

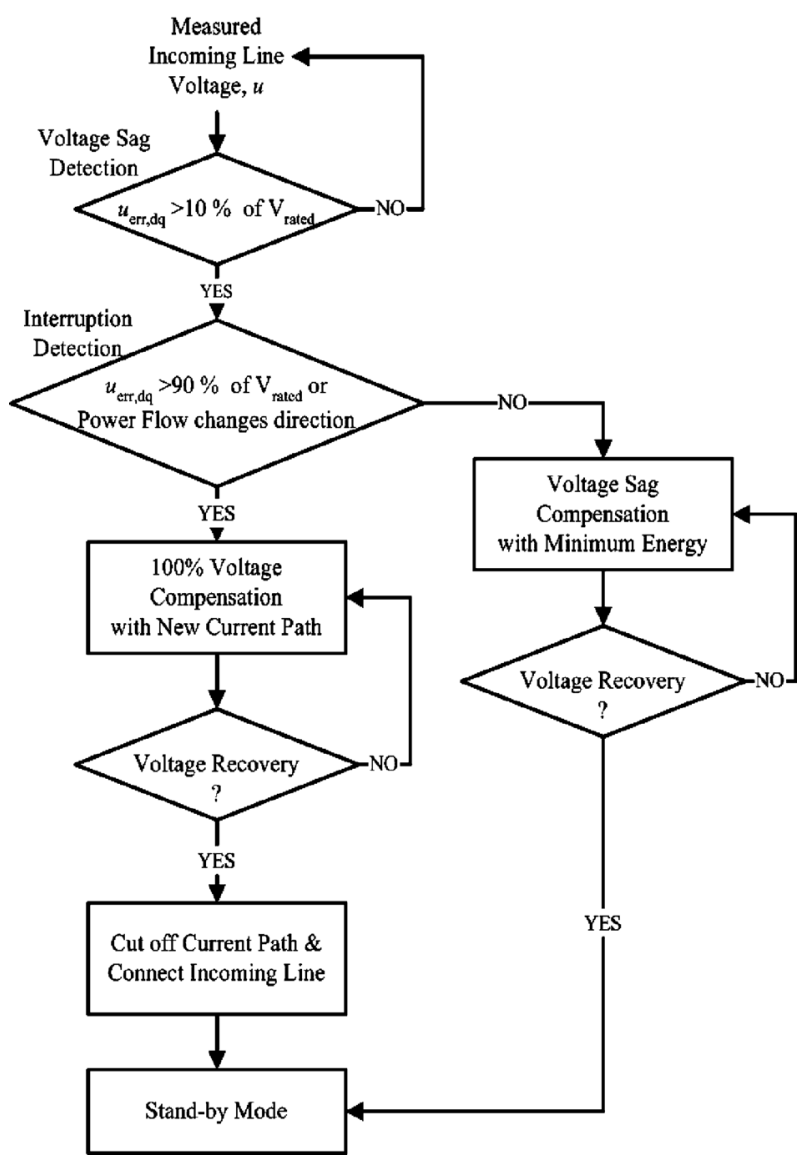

Fig. 7. Flowchart of control algorithm given in Eqs. (7) and (8) as follows:

$$
\left|\bar{u}_{\text {error }, d q}\right|>u_{\text {Threshold }} \text {. }
$$

where the rms of the error is

$$
\left|\bar{u}_{\text {error }, d q}\right|=\sqrt{\left(u_{\text {ref }, d}-u_{\text {supply }, d}\right)^{2}+\left(u_{r e f, q}-u_{\text {supply }, q}\right)^{2}}
$$

The voltage sag will be detected if the error voltage is higher than $10 \%$ of the rated voltage, which is set as $u_{\text {Threshold }}$. The block diagram for the error voltage vector detection is shown in Fig. 8. The $d-q$ decomposition and low-pass filter will be used to acquire the fundamental positive sequence of the incoming line voltage. If a voltage disturbance occurres, the Freeze signal will trig the holder to sample the fundamental positive sequence voltage and will be used as reference voltage, then the error voltage vector can be obtained as calculated from Eqs. (7) and (8).

There are two methods used for the interruption detection. First is based on the rms of the error vector voltage, where the threshold voltage is set as $90 \%$ of the rated voltage. Another interruption detection method is based on the active power flow direction. During voltage sag compensation, the incoming power $\left(\mathrm{P}_{\mathrm{T}}\right)$ and injected power $\left(\mathrm{P}_{\mathrm{C}}\right)$ supply load as shown in Fig. 9(a). If the circuit breaker is opened, the direction of $\mathrm{P}_{\mathrm{T}}$ will change into the opposite direction as shown in Fig. 9(b). The interruption will be detected if $\mathrm{P}_{\mathrm{T}}$ changes

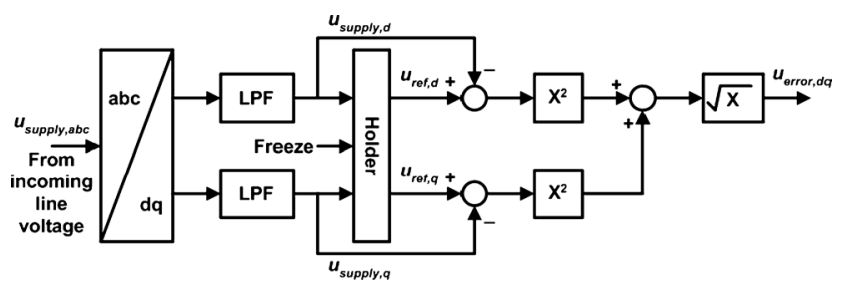

Fig. 8. Block diagram for error voltage detection

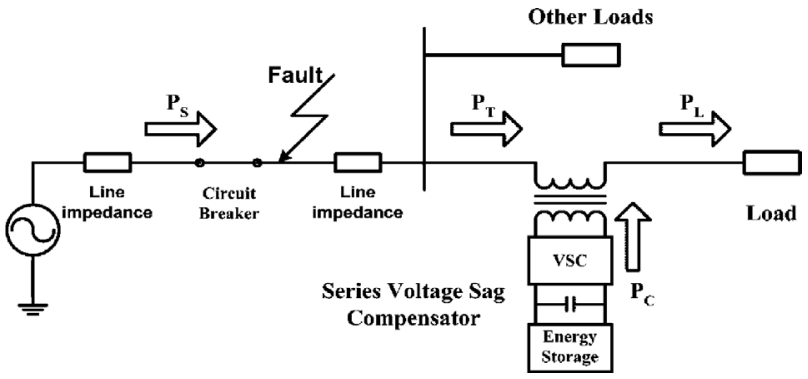

(a) With circuit breaker closed

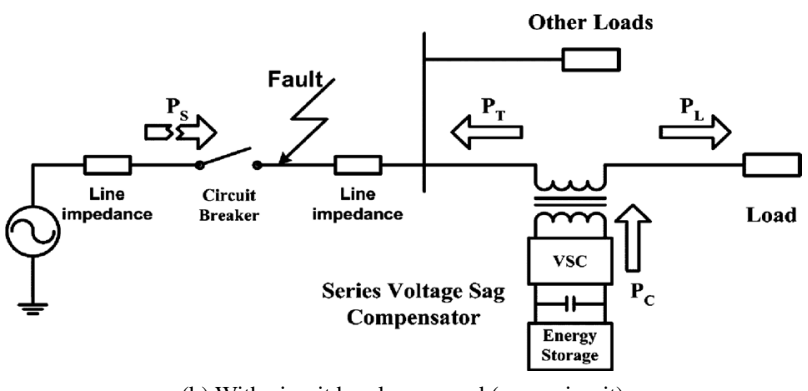

(b) With circuit breaker opened (open-circuit)

Fig. 9. Power flow in the system with voltage compensation during fault occurred 


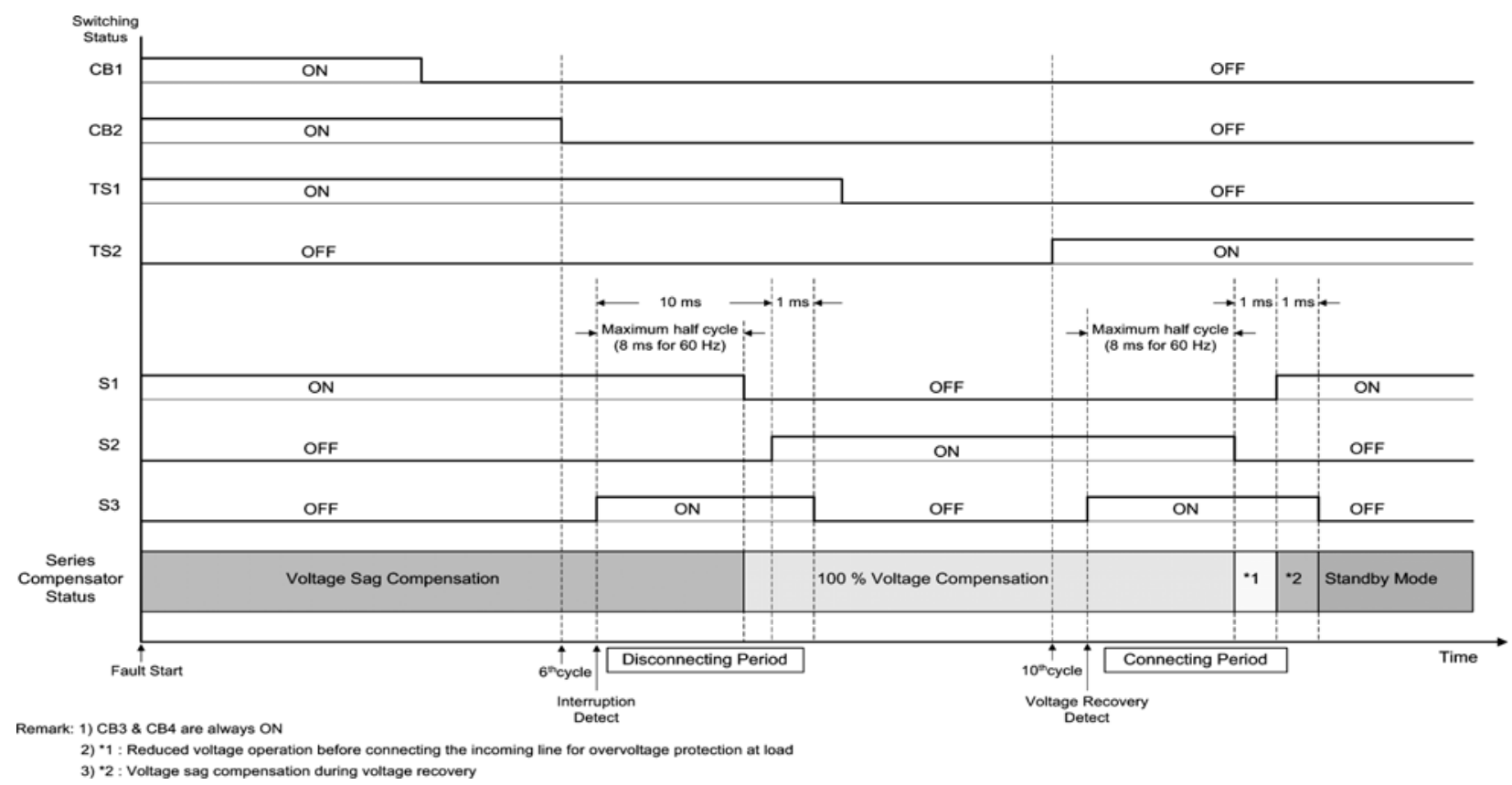

Fig. 10. Time chart of the switch operation using series voltage sag compensator with open-circuit protection

its polarity. These two methods are used together in order to ensure that the interruption is occurred.

3.3 Control Scheme of Switches According to Fig. 3, at the beginning of the fault occurrence, the circuit breaker CB1 and CB2 still connect the current path for the load. The compensator will compensate for the voltage sag. After opening CB1 and CB2, the interruption is detected. The incoming line will be cut off by switch $\mathrm{S} 1$ and the new current path will be made by switch S2. The inverter will supply $100 \%$ AC voltage to the load. After TS2 is closed, the voltage recovery is detected. The current path made by switch S2 will be opened and the incoming line will be connected to the load by switch $\mathrm{S} 1$, then the series compensator will enter the standby mode. During disconnecting and connecting the incoming line, 2 requirements are needed as follows;

1) continuous current path must be maintained to load and

2) new current path must not cause short-circuit current of utility source after the voltage recovery.

The switching sequence procedure to disconnect the incoming line and connect the new current path is as follows:

Disconnecting the incoming line- After the interruption is detected, the switch $\mathrm{S} 1$ is commanded to be turned off and the switch S3 is commanded to be turned on. From the switch characteristics, switch S3 can be instantaneously turned on while switch $\mathrm{S} 1$ needs the turn-off time (the thyristors in switch S1 will turn off at the first zero-crossing current). The maximum turn-off time is half cycle (about $8 \mathrm{~ms}$ for $60 \mathrm{~Hz}$ ). The measured voltage at the incoming of the charging circuit becomes the voltage drop across the charging circuit impedance.

Connecting the new current path- After the interruption is detected, switch S2 is commanded to be turned on and it needs $10 \mathrm{~ms}$ to be completely turned on. After switch S2 is completely turned on, the switch $\mathrm{S} 3$ will be on for $1 \mathrm{~ms}$ in order ensure the continuous current path to load. Because of the voltage drop across the charging circuit impedance and the $100 \%$ maximum limit of voltage compensation, the load voltage will experience a voltage sag during the use of the charging circuit as current path.

The switching sequence procedure to disconnect the new current path and connect the incoming line the is as follows:

Disconnecting the new current path- After the voltage recovery is detected, the switch S2 is commanded to be turned off and the switch S3 is commanded to be turned on. The high-speed mechanical switches in switch S2 will be turned off at the first zero-crossing current. The maximum turn-off time is half cycle (about $8 \mathrm{~ms}$ for $60 \mathrm{~Hz}$ ). The switch S1 cannot be turned on before the switch S2 is completely turned off, because a short circuit will occur to the incoming line.

Connecting the incoming line- After S2 is completely turned off, switch S1 needs time $1 \mathrm{~ms}$ before it is turned on. The switch S1 can instantaneously be turned on but the overvoltage will occur to the load as the compensator supply $100 \%$ voltage. Therefore, before switch S1 is turned on, the injected voltage must be reduced so the sum of the incoming line voltage and injected voltage will not exceed the nominal voltage at load after connecting the incoming line. After switch S1 is completely turned on, the switch S3 will be on for $1 \mathrm{~ms}$ in order ensure the continuous current path to load. The load voltage will experience a voltage sag due to the use of the charging circuit as the current path and transient overvoltage protection scheme at load.

Fig. 10 illustrates the time chart of the switch operation in the transmission system with a transfer switch using the series voltage sag compensator with open-circuit protection.

\section{Simulation Results}

4.1 Circuit Model and Parameters The computer simulation was carried out with the transmission system model as shown in Fig. 11. The parameters in the model are based on the real transmission system and using 1000 MVA per unit base. The parameters of the series voltage sag compensator that can compensate $100 \% \mathrm{AC}$ voltage are given in 
Table 1 . The charging operation will not operate during voltage sags, so the minimum input voltage for charging operation is $90 \%$ of the incoming line voltage. Then, the minimum rectified output voltage for charging operation is calculated as $1.2 \mathrm{kV}$. The dc bus voltage, the output current and the switching frequency were chosen to be $2 \mathrm{kV}, 1 \mathrm{kA}$ and $1 \mathrm{kHz}$, respectively. As a result, the minimum inductance for

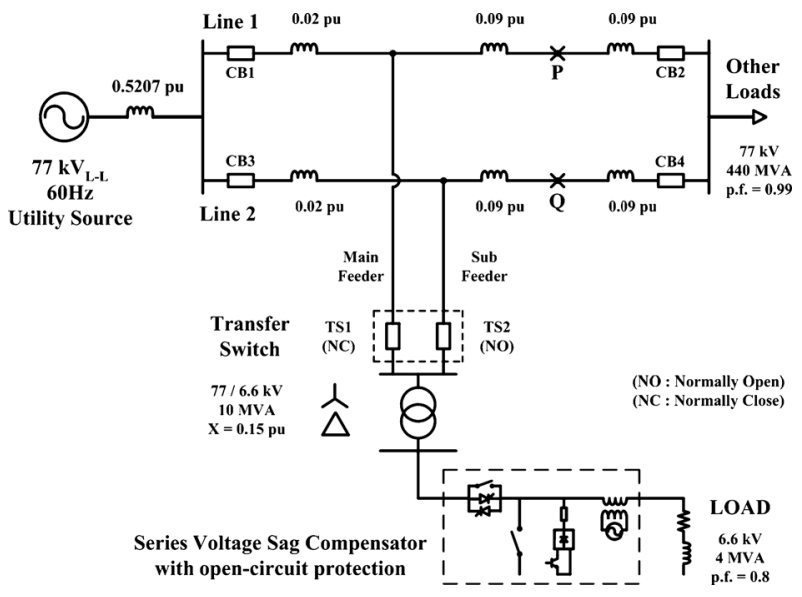

Fig. 11. System model for computer simulation

Table 1. Parameters of series voltage sag compensator with open-circuit protection

\begin{tabular}{|c|c|}
\hline \multicolumn{2}{|c|}{ Series Inverter } \\
\hline Series transformer & $3.81 \mathrm{kV}: 1.5 \mathrm{kV}, 1.63 \mathrm{MVA}, \mathrm{X}=3 \%$ \\
$\mathrm{R}_{\mathrm{l}}+\mathrm{R}_{\mathrm{e}}$ & $0.27 \Omega$ \\
AC-side filter & $\mathrm{C}_{\mathrm{F}}=100 \mu \mathrm{F}, \mathrm{R}_{\mathrm{D}}=2.4 \Omega$ \\
PWM control & $\mathrm{f}_{\text {carrier }}=7.2 \mathrm{kHz}$, unipolar PWM \\
\hline \multicolumn{2}{|c|}{ Charging Circuit } \\
\hline 3-phase transformer & $6.6 \mathrm{kV}: 1 \mathrm{kV}, 4 \mathrm{MVA}, \mathrm{X}=10 \%$ \\
Input line inductor $\left(\mathrm{L}_{\mathrm{f}}\right)$ & $50 \mu \mathrm{H}$ \\
DC inductor $(\mathrm{L})$ & $0.5 \mathrm{mH}$ \\
DC capacitor $(\mathrm{C})$ & $500 \mathrm{mF}$ \\
DC bus voltage & $2 \mathrm{kV}$ \\
\hline
\end{tabular}
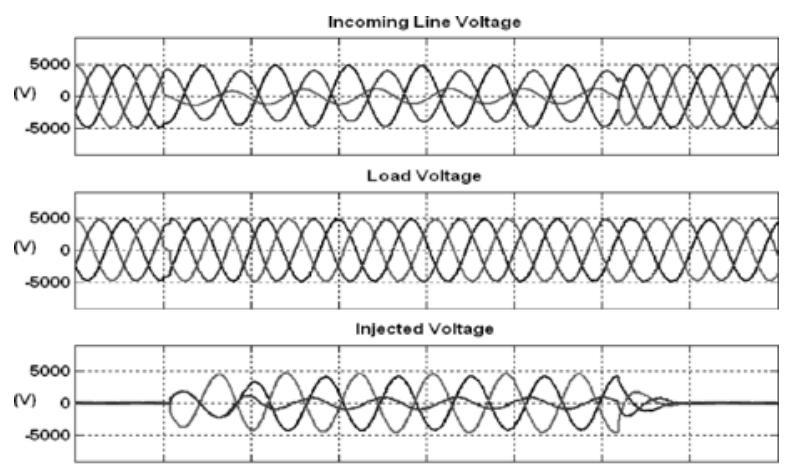

Incoming Line Current

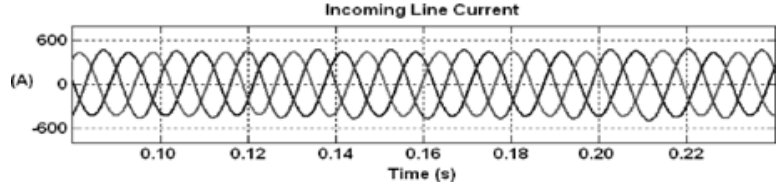

Fig. 12. Simulation results for voltage sag compensation from two-phase fault
$\mathrm{L}$ is calculated as $0.144 \mathrm{mH}$, with $I_{o B, \max }=1 \mathrm{kA}, V_{o}=2 \mathrm{kV}$, $f_{s}=1 \mathrm{kHz}$ and $D=0.4$. The maximum rectified output voltage is $1.35 \mathrm{kV}$. The rectified load current is calculated as $350 \mathrm{~A}$ and the system frequency is $60 \mathrm{~Hz}$. The transformer ratio was chosen to be 6.6 As a result, the maximum inductance for $\mathrm{L}$ is calculated as $1.55 \mathrm{mH}$, with $I_{\text {Load,rectified }}=350 \mathrm{~A}$, $V_{d c, \max }=1.35 \mathrm{kV}, \omega=60 \mathrm{~Hz}$ and $n=6.6$. The $0.5 \mathrm{mH}$ $\mathrm{dc}$ inductor was chosen to ensure the continuous-conduction mode and limit the transient dc voltage drop within $33 \%$.

4.2 Voltage Sag Case A two-phase fault was applied at point $\mathrm{Q}$ in the transmission line in order to cause a 0.1 second voltage sag at the receiving terminal of the load. The circuit breakers CB3 and CB4 in Line 2 will be opened after 5 and 6 cycles, respectively. With the given system model, the simulation results for voltage sag compensation by using minimum energy control algorithm ${ }^{(5)}$ is shown in Fig. 12.

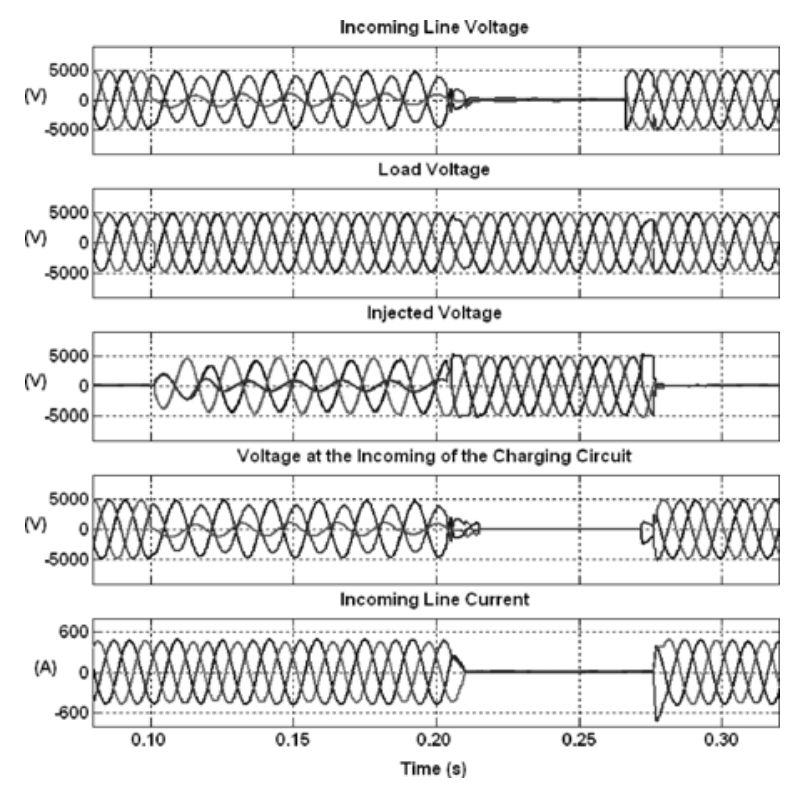

(a) Voltage compensation during fault occurred
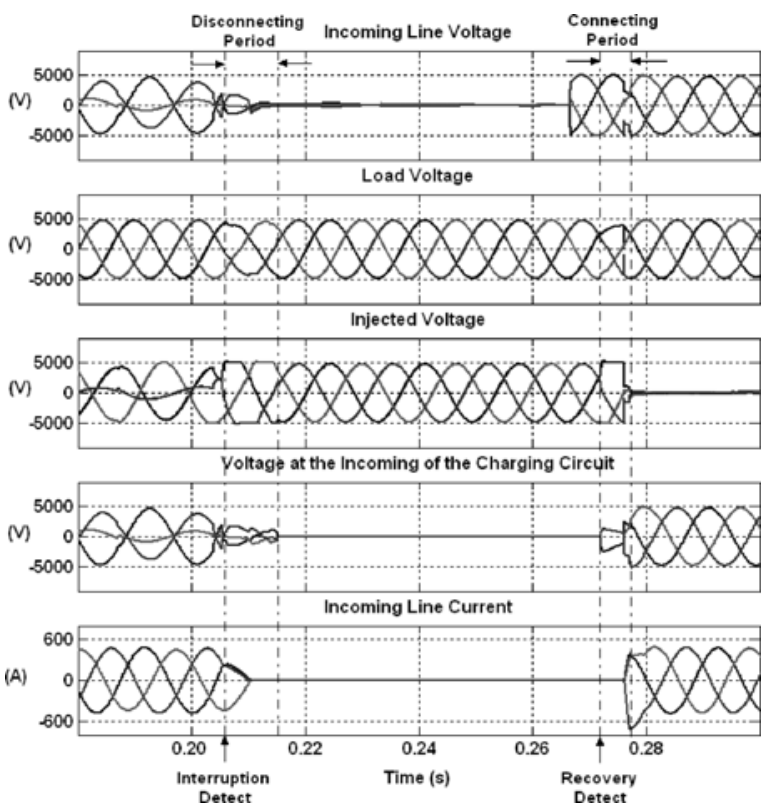

(b) Voltage compensation during the interruption (zoom version of (a))

Fig. 13. Voltage compensation from two-phase fault 


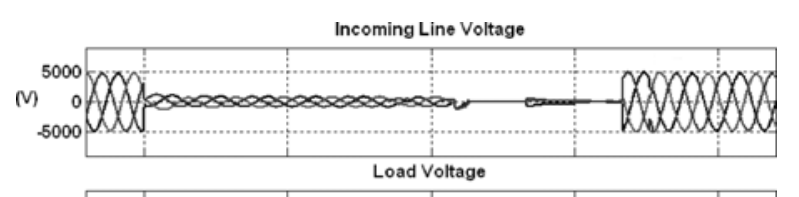

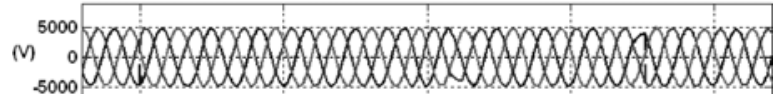

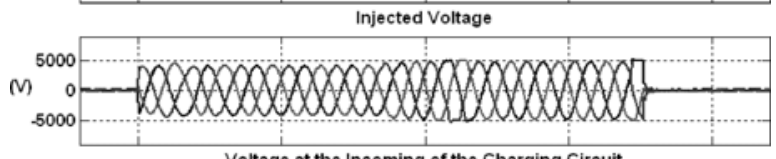

Volthe Incoming of the Charging Circuit
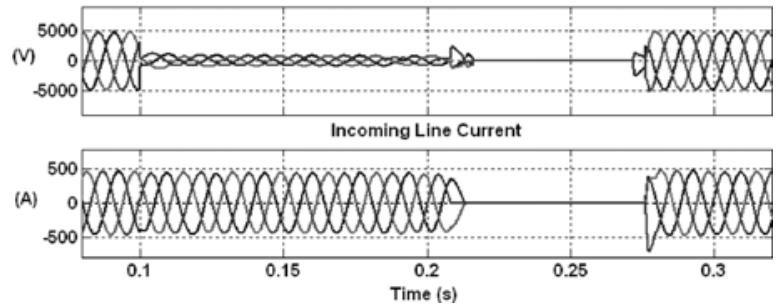

(a) Voltage compensation during fault occurred
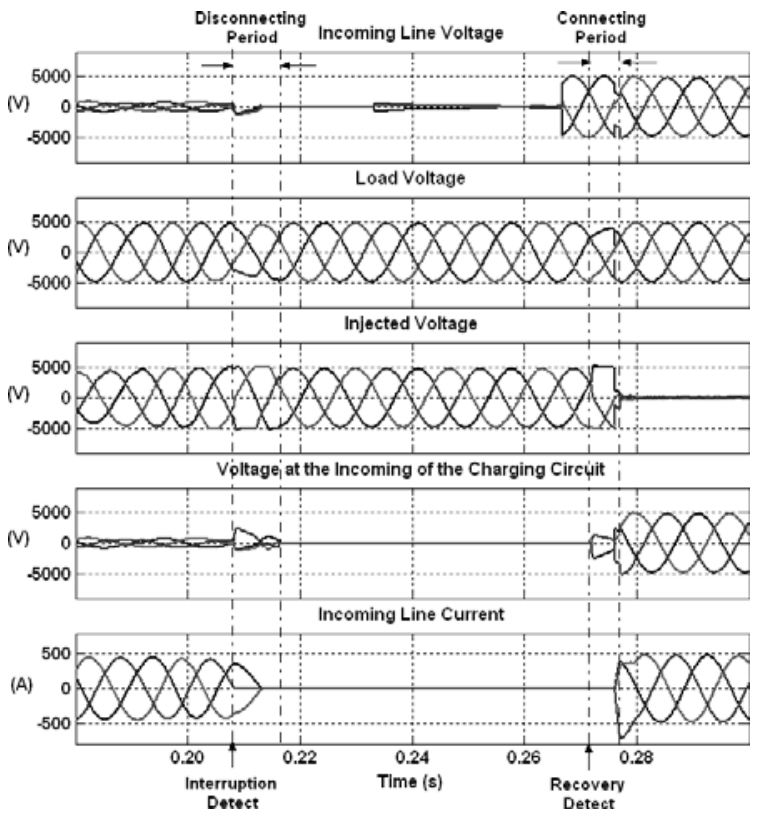

(b) Voltage compensation during the interruption (zoom version of (a))

Fig. 14. Voltage compensation for three-phase fault

The series voltage sag compensator operated in voltage sag compensation mode where the switch S1, S2 and S3 remained their status. The load voltage during compensation is balanced and exhibits neither transient overvoltage nor oscillations during the recovery of voltage.

4.3 Interruption Case The two-phase fault and three-phase fault were applied at point $\mathrm{P}$ in the transmission system model in order to cause an interruption at the load. The simulation results of voltage compensation from the twophase fault and three-phase fault occurred in the transmission line are given in Figs. 13 and 14. At the starting of voltage compensation, where the circuit breakers were still closed, the voltage sag compensation algorithm was used as shown in Figs. 13(a) and 14(a). After the interruption was detected, the interruption compensation algorithm was used and the switches S1, S2 and S3 were operated to cut off incoming and make new current path. The compensator injected $100 \%$

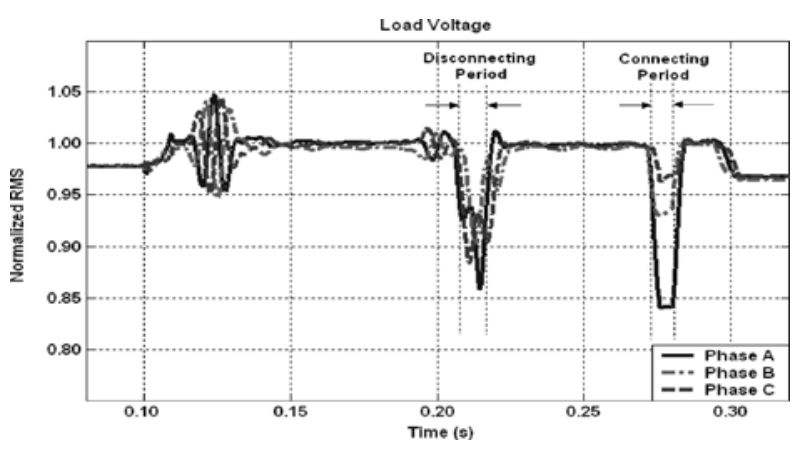

(a) Two-phase fault case

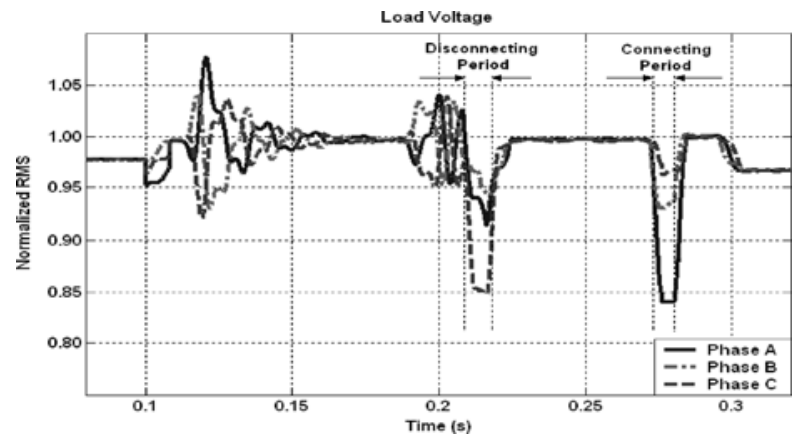

(b) Three-phase fault case

Fig. 15. Compensated load voltage during fault occurred

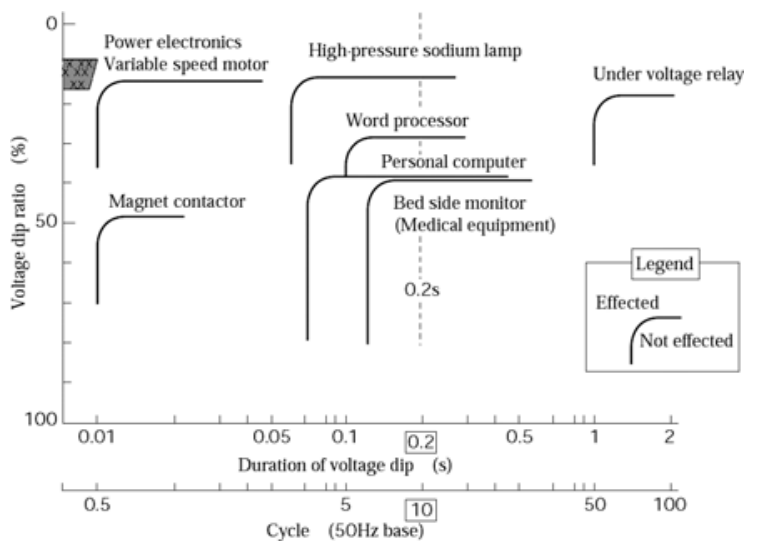

Fig. 16. Effectiveness of voltage sag on electrical loads

voltage compensation to the load during the interruption interval. After the voltage recovery detection, the switches S1, $\mathrm{S} 2$ and $\mathrm{S} 3$ were operated again to connect the incoming line and disconnect the temporary current path. The load voltage during compensation is well compensated but it has a voltage sag condition at the beginning and ending of the interruption as shown in Fig. 13(b) and 14(b).

The compensated load voltage in per unit during fault occurred is shown in Fig. 15(a) and 15(b). The duration of voltage drop under $90 \%$ during the disconnecting and connecting period are 2 and $6 \mathrm{~ms}$ for two-phase fault case, and 7 and $6 \mathrm{~ms}$ for three-phase fault case. Fig. 16 shows the effectiveness of voltage sag on electrical loads ${ }^{(7)}$, where the duration of load voltage under $90 \%$, is shown in the shaded area. According to this, the transient voltage sag will not affect the normal operation of electrical loads.

\section{Conclusion}

The compensating characteristics of series voltage sag 
compensator using series type SMES with open-circuit protection in transmission system with a transfer switch have been presented. The proposed circuit configuration included the additional hybrid switch and new current path circuit is applied with the series voltage sag compensator, so the continuous power will be maintained to critical loads under disturbances instantaneously. The simulation results showed the well-compensated and balanced load voltage characteristics during the voltage sag and interruption occurred. The small voltage sag could occur during the disconnecting and connecting period of the interruption compensation at the acceptable level that will not affect the electrical loads.

(Manuscript received Aug. 30, 2004, revised June 16, 2005)

\section{References}

( 1 ) T.R. Abel : "The United States Air Force's micro-superconducting magnetic energy storage technology insertion program project results", in Proc. Power Quality'97/Power Value'97, pp.404-417, Baltimore, USA (1997)

(2) G.T. Heydt, et al.: "Simulation and Analysis of Series Voltage Boost Technology for Power Quality Enhancement”, IEEE Tans. Power Delivery, Vol.3, No.4, pp.1335-1341 (1998)

( 3 ) T. Wunderlin, et al.: "Power Supply Quality Improvement with a Dynamic Voltage Restorer (DVR)", Proc. 1998 International Conference on Energy Management and Power Delivery, pp.518-525, Singapore (1998)

( 4 ) S.S. Choi, B.H. Li, and D.M. Vilathagamuwa: "Dynamic Voltage Restoration with Minimum Energy Injection”, IEEE Trans. Power Systems, Vol.15, No.1, pp.51-57 (2000)

( 5 ) S. Polmai, T. Ise, and S. Kumagai: "Configuration of a Voltage Sag Compensator by Use of a Micro-SMES and Its Experimental Results", Trans. IEE of Japan, Vol.123-D, No.1, pp.30-37 (2003-1) (In Japanese)

( 6 ) S.W. Middlekauff, et al.: "System and customer impact: considerations for series custom power devices", IEEE Trans. on Power Delivery, Vol.13, No.1, pp.278-282 (1998)

( 7 ) M. Takeda, et al.: "Development of a Novel Hybrid Switch Device and Application to a Solid-State Transfer Switch", IEEE/PES Winter Meeting, Vol.2, pp.1151-1156 (1999)
( 8 ) Electric Technology Research Association: "Voltage Sags Counter Measures”, Electric Cooperative Research, Vol.4, No.3 (1990) (In Japanese)

Sumate Naetiladdanon (Student Member) recieved his M.Sc. degree

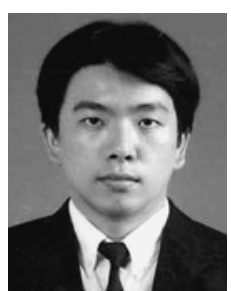
in Electric Power Engineering from Rensselaer Polytechnic Institute, NY in 1999. He joined the Department of Electrical Engineering of King Monkut's University of Technology Thonburi in 2001. He is currently a Ph.D. student at Osaka University. His research interests are included voltage sag compensation and high power electronics application with power systems.

Toshifumi Ise (Member) received the Doctor of Engineering de-

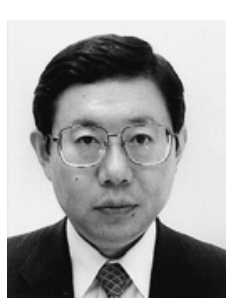
gree in electrical engineering from Osaka University, Japan in 1986. Currently, he is the professor of Department of Electrical Engineering at Osaka University. His research interests are in the areas of power electronics and applied superconductivity including superconducting magnetic energy storage (SMES) and new distribution system.

Hideki Fujita (Member) Hideki Fujita received his B.S. and Ph.D.

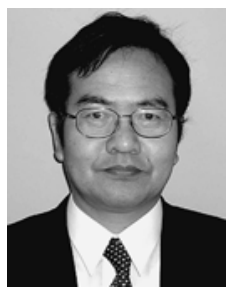
degree in electrical engineering from Nagoya University in 1973 and 1995. He joined Chubu Electric Power Co., Inc. in 1973 and is presently a Chief Managing Research Engineer of the Electric Power Reserch \& Development Center. His main field of interest is power system application using new equipment such as SMES. 